\title{
REVIEW \\ Economic Evaluation of Agricultural Mitigation and Adaptation Technologies for Climate Change: Model Development for Impact Analysis and Technological Assessment
}

\author{
Jun FURUYA ${ }^{1 *}$, Suminori TOKUNAGA ${ }^{2}$, Mitsuru OKIYAMA ${ }^{3}$, Yuko AKUNE ${ }^{2}$, \\ Yoji KUNIMITSU ${ }^{4}$, Hideo AIZAKI ${ }^{5}$ and Shintaro KOBAYASHI ${ }^{1}$ \\ ${ }^{1}$ Social Sciences Division, Japan International Research Center for Agricultural Sciences (Tsukuba, \\ Ibaraki 305-8686, Japan) \\ ${ }^{2}$ Faculty of Economics and Business Administration, Reitaku University (Kashiwa, Chiba 277-8686, \\ Japan) \\ ${ }^{3}$ Reitaku Institute of Political Economics and Social Studies, Reitaku University (Kashiwa, Chiba \\ 277-8686, Japan) \\ ${ }^{4}$ Rural Development and Planning Division, National Institute of Rural Engineering, National \\ Agriculture and Food Research Organization (Tsukuba, Ibaraki 305-8609, Japan) \\ ${ }^{5}$ Chair of Agricultural and Resource Economics, Division of Bio-systems Sustainability, Research \\ Faculty of Agriculture, Graduate School of Agriculture, Hokkaido University (Sapporo, Hokkaido \\ 060-8589, Japan)
}

\begin{abstract}
Agricultural mitigation and adaptation technologies developed and assessed in a project organized by the Agriculture, Forestry, and Fisheries Research Council were evaluated on an economic basis using a regional-production model, an applied general-equilibrium model, a discrete choice experiment, and a world-food model. Climate-change effects on food production were also evaluated using these models. This paper presents: (1) an overview of the sub-project structure and goals, (2) the six results of the sub-project, and (3) the future direction of the sub-project. Results of these models were subsequently integrated into a single regional model, whereupon selected technologies were economically evaluated using the models developed in the sub-project. The main results are as follows: (1) delaying the introduction of high-temperature-tolerant rice by one year will result in an average economic welfare losses of 429 million yen per year in Japan; (2) higher temperatures under RCP4.5 scenario will cause an increase in $0.2 \mathrm{t} \mathrm{ha}^{-1}$ rice yield in Japan in 2040s compared to a constant climate variables case; (3) the target reduction rate of GHG, which is $25 \%$ of the 1990 figure, will imply benefit-cost ratios greater than one for most $\mathrm{CH}_{4}-$ suppression technologies developed in the project.
\end{abstract}

Discipline: Agricultural economics

Additional key words: Choice experiment, Dynamic computable general-equilibrium model, Regional production model, World-food model

\section{Introduction}

The Intergovernmental Panel on Climate Change (IPCC) reports that, by the end of this century, global temperatures are expected to increase $4.8^{\circ} \mathrm{C}$, raising sea-levels by $82 \mathrm{~cm}$ compared to levels prevailing in 2000 (IPCC 2013). Those higher temperatures are expected to affect food production. Peng et al. (2004) reported that if the minimum temperature during the growing season were to increases by $1{ }^{\circ} \mathrm{C}$, the rice yield in the dry season would decrease by $10 \%$. West et al. (2003) reported that if the mean temperature were to increase by $1{ }^{\circ} \mathrm{C}$, the milk yield of Holstein cattle could be expected to decrease by $0.88 \mathrm{~kg}$ day $^{-1}$.

Measures by the food-production sector to counter climate change are necessary to prevent decreased production. The Agriculture, Forestry, and Fisheries Research Council (AFFRC) of the Ministry of Agriculture, Forestry, and Fisheries (MAFF) of Japan has organized a project team to

*Corresponding author: e-mail furuya@affrc.go.jp

Received 11 October 2013; accepted 10 October 2014. 


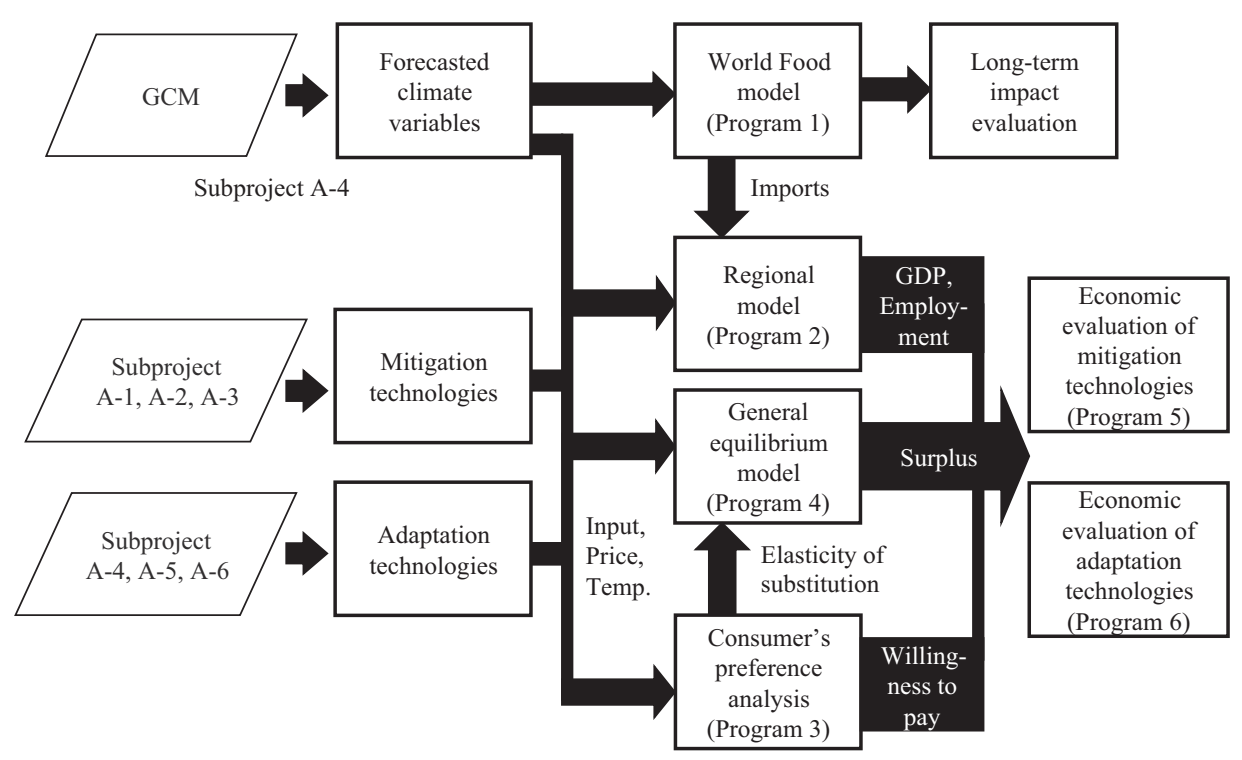

Fig. 1. Relations among sub-projects and programs

develop mitigation and adaptation technologies for food and forest products and adapt to climate change. This paper introduces research activities of a sub-project team to economically evaluate mitigation and adaptation technologies of agricultural products.

To evaluate such technologies, three types of econometric models are used: the regional agricultural-production model, the general-equilibrium model, and the world-food model. The impacts of climate change on the food market and other industries are also analyzed using these models. These econometric evaluations of measures to counter climate change are groundbreaking approaches. Outlines and some results of the economic evaluation project are presented herein.

\section{Projects and time period}

\section{Projects}

The main project to develop technology for measures to counter climate change comprises seven sub-projects: A1 (Yagi 2013), A-2, and A-3 - development of mitigation technologies of agriculture, forestry, and fisheries for climate change; A-4, A-5, and A-6 - development of adaptation technologies of agriculture, forestry, and fisheries for climate change; and A-7 - economic evaluation of agricultural mitigation and adaptation technologies for climate change. The Japan International Research Center for Agricultural Sciences (JIRCAS), the National Institute of Rural Engineering (NIRE) of National Agriculture and Food Research Organization (NARO), the University of Tsukuba, the University of Hokkaido, and Reitaku University are leading sub-project A-7.

The economic evaluation sub-project includes six pro- grams: (1) evaluation of the global-warming impact on the supply and demand of food in Japan and worldwide; (2) the impact of mitigation and adaptation technologies for climate change on regional agriculture, forestry and fisheries; (3) evaluation of consumer preferences for agricultural products using mitigation technologies; (4) quantitative evaluation of changes in consumer surplus introducing mitigation and adaptation technologies; (5) economic evaluation of mitigation technologies developed by sub-projects A-1, A-2, and A-3; and (6) economic evaluation of adaptation technologies developed by sub-projects A-4, A-5, and A-6.

Figure 1 depicts the relations among sub-projects and programs in the sub-project involving economic evaluation of mitigation and adaptation technologies of agriculture, forestry, and fisheries. The forecast and actual climate variables are provided from sub-project A-4, whereupon these data are fed into the world-food model, regional, and computable general-equilibrium (CGE) models respectively. The world-food model analyzes the long-term effects of climate change on the food supply of global nations. Some information related to mitigation and adaptation technologies of agriculture, for example, the effects of introducing varieties capable of tolerating higher temperatures, are used in the regional and CGE models. The CGE model includes substitution elasticities between traditional products and those for which measures to counter climate change are implemented, as estimated using consumer-preference analysis. Analyses using the three models provide precise and accurate technology assessments. However, it is difficult to assess the effects of many technologies developed in other sub-projects. Solving this problem, cost-benefit analyses are used to assess the mitigation technologies and a simple model based on the input-output model is developed to 
assess the adaptation technologies.

(1) Program 1: Global-warming impact on world-food markets

The world-food model, which is useful to evaluate the long-term impacts of climate change on agricultural markets, is developed in this program. Forecast climate and macroeconomic variables according to Special Report on Emission Scenarios (SRES) or Representative Concentration Pathways (RCP) are inserted into the world-food model as exogenous variables and the impacts of climate change on the food supply of each country are evaluated using the world-food model and respective scenarios.

(2) Program 2: Impact of mitigation and adaptation technologies on regional industry

The impacts of disseminating adaptation technologies on agricultural production in eight regions of Japan, i.e., Hokkaido, Tohoku, Kanto, Hokuriku, Tokai, Kinki, Chugoku and Shikoku, and Kyushu, are analyzed using econometric models and Social Account Matrices (SAM) in each region are produced to develop the regional agricultural model. The estimated parameters are then used in the regional general-equilibrium model.

(3) Program 3: Consumer-preference analysis

Substitutability between imported and domestic goods produced using mitigation technologies is analyzed using the multi-attribute stated preference method, while the estimated elasticities of substitution are used to analyze changes in consumer preferences.

(4) Program 4: Changes in consumer surplus introducing mitigation and adaptation technologies

The dynamic applied general-equilibrium model, with the agricultural sector subdivided to main agricultural products, was developed to produce an outlook for the next century. The introductions of adaptation technologies to climate change were evaluated according to changes in the consumer surplus measured by equivalent variation values, based on the price and quantity of goods in the model.

(5) Program 5: Economic evaluation of mitigation technologies developed in the project

The emission reductions of greenhouse gases (GHG) and the costs of introducing mitigation technologies developed in other sub-projects, i.e., A-1, A-2, and A-3, are gathered for the economic evaluation of the technologies. The effects of disseminating the mitigation technologies are also quantified according to the cost-benefit ratio and other parameters, whereupon this information was fed back to the researchers having developed these technologies.

(6) Program 6: Economic evaluation of adaptation technologies developed in the project

Production of crop, livestock, and fishery commodities will be decreased by global warming. Adaptation technologies are expected to see production recover from decline. The production-recovery rates for global warming and the costs of introducing the technologies developed in the other sub-projects, i.e., A-4, A-5, and A-6, are gathered for the economic evaluation of such technologies. The effects of disseminating the adaptation technologies are then evaluated using a simple input-output model, whereupon this information is fed back to the researchers having developed these technologies.

\section{Time period and target area}

The project covers the five year period 2010-2014 and an interim assessment was conducted in 2011. The themes of sub-project A-7 were conducted according to the initial plan. The target area includes all of Japan. The impacts of climate change on crop imports from foreign countries to Japan will also be analyzed using a world-food model.

\section{Uniqueness of the project}

Most sub-projects involving development of mitigation and adaptation technologies to climate change have specifically addressed the physical effects of such technologies, such as the production-recovery rate to global warming. Considering the effects of implementing developed technologies on society, economic evaluations of such technologies developed in main projects are necessary. Analyses according to the technologies' cost-benefit and ripple effects throughout the regional and national economy are conducted using econometric models in sub-project A-7.

Tran \& Daim (2008) categorized methods of technological assessment for the public decision-making domain and for business uses. In their study, structural modeling and system dynamics are categorized as a method of public decision-making, while the cost-benefit analysis is categorized as a method for business uses. The assessment models are selected according to users of the results in sub-project A-7. Some selected adaptation technologies were evaluated using structural models. The assumed users of the results are policymakers. Most mitigation technologies developed in the project are evaluated using cost-benefit analysis. The users are assumed to be the researchers who developed these technologies.

\section{Results}

Some analytical results in each program are selected, while the precise analytical results will be provided in JARQ 49(2). The following six selected results are presented in order of the program numbers:

\section{Impact analysis of climate change on global crop production}

A world-food model capable of analyzing the impact of climate change was developed by Furuya \& Koyama 


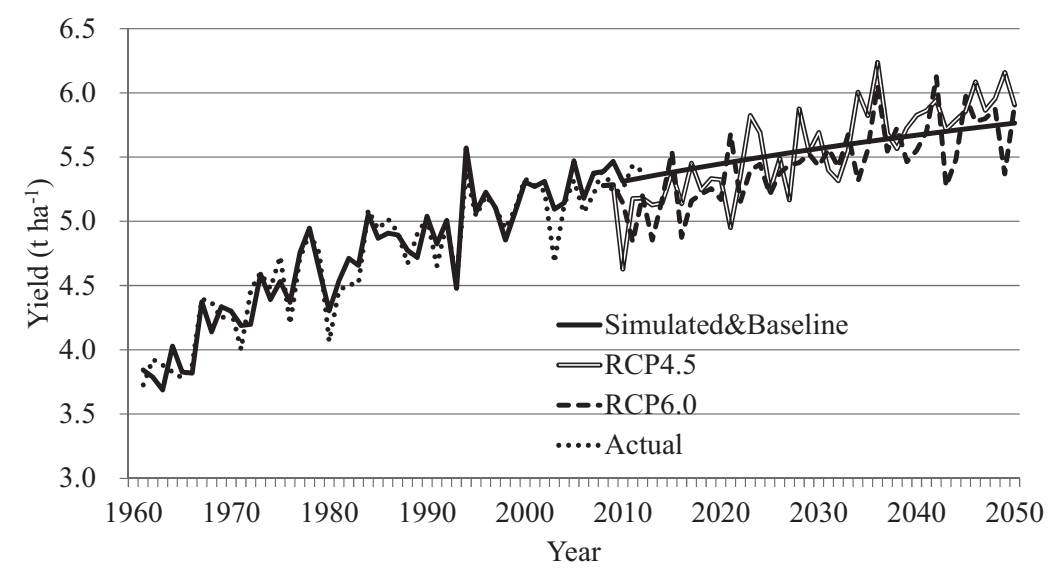

Fig. 2. Change in rice yield in Japan

(2005) and is relevant to the mid-term outlook for 20-30 years. Another model including a long-term outlook for 50-100 years was developed and yield trends of rice, wheat, maize, and soybeans were obtained by estimating the logistic functions or linear functions with a logarithmic timetrend term for the long-term outlook. Furthermore, temperature and solar radiation elasticities of yields were calculated using a crop model of the FAO (Doorenbos \& Kassam 1979). The crop model was then modified by introducing cubic-spline interpolation and logistic functions. These elasticities of climate variables were inserted into the yield-trend functions whereupon the global effects of temperature and solar radiation changes on crop yields were analyzed (Furuya et al. 2015). The changes in yields of two simulations using climate variables under the Representative Concentration Pathways (RCP) scenarios of the IPCC Fifth Assessment Report (AR5) were compared with the baseline, for which climate variables were fixed. The RCP4.5 and RCP6.0 scenarios assume that radiative forcings are stabilized respectively to $4.5 \mathrm{~W} \mathrm{~m}^{-2}$ and $6.0 \mathrm{~W} \mathrm{~m}^{-2}$ by 2100 . Those are, respectively, equivalent to $\mathrm{CO}_{2} 650 \mathrm{ppm}$ and 850 ppm.

Figure 2 portrays changes in the yield of rice in Japan as an example of the simulation. Climate change pushes up the yield slightly. Yields of the RCP4.5 and RCP6.0 scenarios are expected to be $5.91 \mathrm{t} \mathrm{ha}^{-1}$ and $5.73 \mathrm{tha}^{-1}$ respectively, on average, during 2041-2050, although the baseline yield, for which climate variables are fixed on those in the base year 2008, is expected to be $5.72 \mathrm{t} \mathrm{ha}^{-1}$ in the same year. Results of geographical analyses show that rice, wheat, maize, and soybeans production in low-latitude countries is expected to be affected by climate change. Especially, climate change is expected to decrease wheat and maize production in sub-Saharan African countries in the 2040s, whereas their productions in the region reaps a benefit from higher temperatures in the 2020s.

\section{Evaluation of high-temperature-tolerant rice variety}

Technologies developed to adapt rice production methods to climate change on Japanese agricultural production were evaluated using the dynamic computable general equilibrium (DCGE) model (Akune et al. 2015). The recent increasing temperature trend led to a nationwide decline in rice quality across Japan. The percentage of first-class rice products was only $62 \%$ in 2010 , despite the usual average of $\geq 80 \%$. The effects of adapting technology to warmer climatic conditions by simulating scenarios with and without high-temperature-tolerant rice were analyzed using the DCGE model, which simulates the effects of high-temperature-intolerant and high-temperature-tolerant rice strains.

For the simulation, it is assumed that if the lowest temperature rise is $1^{\circ} \mathrm{C}$, then the rate of the first-class rice will decrease by $3.57 \%$ on average nationally for traditional rice varieties. Furthermore, it is assumed that the temperature elasticity of the rate of first-class rice is -1.37 for high-temperature-tolerant rice, based on the estimates made by Kawatsu et al. (2007). According to Iizumi et al. (2011), the expected minimum temperature in August will exceed $23^{\circ} \mathrm{C}$ in 2017,2024 , and the years after 2024 . The minimum August temperatures in each prefecture used in the simulation are those of the SRES A1B scenario of the Model for Interdisciplinary Research on Climate (MIROC). The MIROC is the general-circulation model (GCM, a type of climate model) developed by the Center for Climate System Research (CCSR) of the University of Tokyo, National Institute for Environmental Studies (NIES), and the Japan Agency for Marine-Earth Science and Technology (JAMSTEC).

Three scenarios are used in this analysis: Scenarios 1-3. Scenario 1 presents a lack of high-temperature-tolerant rice. Scenario 2 shows the adaptation of high-temperature-tolerant rice since 2017. Scenario 3 shows adaptation from 2024. The timing effects of adapting high-tempera- 
Table 1. Economic welfare of introducing high-temperature-tolerant rice (2005-2030)

\begin{tabular}{lcc}
\hline \hline & $\begin{array}{c}\text { Annual average } \\
\text { welfare loss after 2017 } \\
\text { (billion yen) }\end{array}$ & $\begin{array}{c}\text { Accumulated welfare } \\
\text { loss during 2005-2030 } \\
\text { (billion yen) }\end{array}$ \\
\hline Without high-temperature-tolerant rice & 18.8 & 264 \\
High-temperature-tolerant rice introduced in 2017 & 8.5 & 118 \\
High-temperature-tolerant rice introduced in 2024 & 8.6 & 121 \\
\hline
\end{tabular}

Table 2. Changes in annual farm income, GDP, and consumer surplus by climate change

\begin{tabular}{lrrrrrr}
\hline \hline & & & & \multicolumn{2}{c}{$2051-2100$} \\
& Case $0^{1)}$ & \multicolumn{1}{c}{ Case $1^{2)}$} & Difference & Case 0 & Case 1 & Difference \\
\hline Farm income & 1,045 & 1,029 & -15.6 & 1,167 & 1,146 & -20.7 \\
GDP & 507,467 & 507,487 & 19.8 & 569,811 & 569,845 & 34.9 \\
Consumer surplus & 10,318 & 10,333 & 15.0 & 22,981 & 23,006 & 25.3 \\
\hline
\end{tabular}

Unit: billion yen per year.

1) Case 0: assuming no climate change in future.

${ }^{2)}$ Case 1: assuming climate conditions will change according to the SRES A1B scenario in MIROC.

ture-tolerant rice cultivars are analyzed in comparison with Scenarios 2 and 3 and equivalent variation (EV) is used as a beacon of economic welfare to introduce high-temperaturetolerant rice between 2005 and 2030 under a warmer climate. Actually, EV measures how much extra money a consumer would pay before a price increase. Table 1 presents the EVs for Scenarios 1-3. The annual average welfare loss after 2017 in Scenario 1 is 18.8 billion yen, whereas those in Scenarios 2 and 3 are, respectively, 8.5 and 8.6 billion yen respectively. The total EV in Scenario 2 is -118 billion yen during the simulation period and -121 billion yen in Scenario 3, which simulates the introduction of hightemperature-tolerant rice from 2024. Comparison of the results of timing of adaptation technology reveals that earlier agriculture technological dissemination of high-temperature-tolerant rice would imply a loss of economic welfare (EV), which would be reduced from JPY -121 billion to JPY -118 billion.

\section{Consumers' preference analysis}

The substitution patterns of Japanese consumers between domestically produced and imported agricultural products such as broccoli, kiwifruit, rice, and apples are examined using discrete choice experiments. Furthermore, the time discount rates are measured by these experiments (Aizaki 2014, Aizaki 2015). Economic simulation systems such as CGE modeling have been used to predict the impacts of climate change on the economy and evaluate measures to counter its effects. In these analyses, information related to the substitution between domestic and imported agricultural products is important. However, some agricultural products are not imported during the study. To obtain information related to the hypothetical substitution between domestic and imported goods, experimental choice surveys are administered.

For this study, three web surveys were conducted in January 2011, February 2012, and January 2013 to gather responses to the discrete choice experiment questions for each of the four products and responses were analyzed using the error components multinomial logit model. Results show that, in the case of broccoli and kiwifruit, substitution patterns of imported product with domestic sources are large, although low in the cases of rice and apples.

\section{Impacts of climate change on consumer surplus}

A DCGE model to analyze changes in the consumer surplus is established by estimating parameters using the SAM data based on the input-output table in 2005 (Kunimitsu 2015). The DCGE model includes the total productivity function of rice associated with crop-growth and crop-quality models.

The impacts of climate change on the economy are analyzed using the DCGE model. Table 2 presents changes in farm income, GDP, and consumer surplus as measured by the equivalent variation value. These values were calculated according to the changes in climate variables which are estimated using a GCM: MIROC. The results show that the consumer surplus will increase because the price of rice will decline, corresponding to over-production of rice following climate change. The GDP will increase under climate change amid rising production in the manufacturing sector due to a shift of capital and labor from other sectors. However, the farm income will decrease because prices of rice and land rents will decline below the level if no changes 
Table 3. Benefit-cost ratio of mitigation technologies

\begin{tabular}{cccccccc}
\hline \hline \multirow{2}{*}{ ID } & Mitigation technology & \multicolumn{2}{c}{$\begin{array}{c}\text { Benefit of reduction of one t of } \\
\mathrm{CO}_{2}(10 \text { thousand yen })\end{array}$} & \multicolumn{3}{c}{$\begin{array}{c}\text { Benefit over cost ratio of } \\
\text { reduction of one t of } \mathrm{CO}_{2}\end{array}$} \\
\hline & & \multicolumn{3}{c}{ Target reduction rate } & \multicolumn{3}{c}{ Target reduction rate } \\
& & $7 \%$ & $15 \%$ & $25 \%$ & $7 \%$ & $15 \%$ & $25 \%$ \\
\hline C-1 & Carbon capture \& storage & 3.2 & 7.8 & 17.6 & 0.02 & 0.06 & 0.14 \\
C-2 & Carbon capture \& storage & 3.2 & 7.8 & 17.6 & 0.05 & 0.13 & 0.29 \\
C-3 & Carbon capture \& storage & 5.4 & 13.2 & 29.9 & 0.03 & 0.07 & 0.17 \\
C-4 & Carbon capture \& storage & 9.5 & 23.3 & 52.7 & 0.27 & 0.66 & 1.51 \\
C-5 & Carbon capture \& storage & 7.9 & 19.4 & 43.9 & 0.05 & 0.12 & 0.27 \\
C-6 & Carbon capture \& storage & 3.2 & 7.8 & 17.6 & 0.06 & 0.16 & 0.35 \\
M-1 & Suppression of $\mathrm{CH}_{4}$ & 2.4 & 5.8 & 13.2 & 0.79 & 1.94 & 4.39 \\
M-2 & Suppression of $\mathrm{CH}_{4}$ & 2.4 & 5.8 & 13.2 & 0.39 & 0.97 & 2.20 \\
M-3 & Suppression of $\mathrm{CH}_{4}$ & 0.9 & 2.3 & 5.3 & 0.32 & 0.78 & 1.76 \\
\hline
\end{tabular}

in climate conditions were to occur.

\section{Evaluation of mitigation technologies}

A method of evaluating mitigation technologies was developed and certain mitigation technologies of sub-projects A-1, A-2, and A-3 were evaluated based on responses to a questionnaire in 2010 via experimentation. GHG emission reductions and the costs of introducing these technologies include their target values.

The total cost for introducing a mitigation technology is shown as the following function:

$C=($ cost of introducing the technology $)+($ decrease in production $) \times($ price of the product $)$

The benefit of introducing the mitigation technology is presented as the following function:

$B=(\mathrm{GHG}-$ reduction using the technology $) \times($ social evaluation value per GHG-reduction)

The benefit-cost ratio is calculated by estimating these functions.

The social evaluation value is equivalent to the social marginal cost. The social marginal GHG-reduction costs are, respectively, 16 thousand yen, 39 thousand yen, and 88 thousand yen per $\mathrm{t}-\mathrm{CO}_{2}$ for the national target reduction rates of 7,15 , and $25 \%$. These are average values of some studies conducted before the Great East Japan Earthquake in 2011. The target reduction rates were calculated in comparison to the GHG levels of 1990. Table 3 presents the benefit-cost ratio of agricultural mitigation technologies. Technology M-1 is the most efficient GHG-reduction technology in this project.

\section{Developing a model to evaluate adaptation technologies}

Climate-change adaptation technologies are developed in sub-projects A-4, A-5, and A-6 and two economic models to evaluate these technologies were developed by
Kobayashi et al. (2012) and Kobayashi \& Furuya (2015). One is a simple model that is easy to use by researchers having developed adaptation technologies. The other model is a detailed model based on realistic assumptions. Comparison reveals that the differing reproducibility of international trade induces a difference in projection and a few differences emerged between these two models. However, the simple model is expected to facilitate the evaluation of adaptation technologies.

\section{Direction and use of results}

The outputs of the general-equilibrium and the worldfood models are synthesized into the regional-production model, while effects of the dissemination adaptation technologies are then evaluated using the synthesized model, whereupon the estimated substitution elasticities between domestic and imported products were used to economically evaluate of the technologies.

The mitigation and adaptation technologies developed in the projects were evaluated using cost-benefit analysis and the simple input-output model, whereupon the evaluated results were fed back to the researchers having developed the technologies.

An outline and selected results of the sub-project, aiming to evaluate mitigation and adaptation technologies to climate change, are introduced in this paper. These technologies were evaluated based on supply and demand analyses of some markets and their possible knock-on effects become clear. The economic evaluations of these technologies using econometric models represent unparalleled and groundbreaking studies. It is desired that the system developed in this sub-project contribute to the mitigation and adaptation of farmers to climate change. 


\section{Acknowledgements}

The author acknowledges all members of the climatechange project of the AFFRC who provided information related to mitigation and adaptation technologies developed in the respective sub-projects to the members of sub-project A-7. Furthermore, Dr. Nishimori, a staff member of the National Institute of Agro-Environmental Sciences and sub-project A-4, is greatly appreciated for providing the forecast climate data to members of sub-project A-7.

\section{References}

Aizaki, H. (2014) Technical data on subjective time discount rates measured through a web survey in Japan. Technical Report of the National Institute for Rural Engineering, 215, 219-226.

Aizaki, H. (2015) Examining substitution patterns between domestic and imported agricultural products for broccoli, kiwifruit, rice and apples in Japan. JARQ, 49, 143-148.

Akune, Y. et al. (2015) Economic evaluation of dissemination of high-temperature-tolerant rice in Japan using a dynamic CGE model. JARQ, 49, 127-133.

Doorenbos, J. \& Kassam, A. (1979) Yield response to water, FAO irrigation and drainage paper 33, Food and Agriculture Organization of the United Nations, Rome, Italy, pp.193.

Furuya, J. \& Koyama, O. (2005) Impacts of climatic change on world agricultural product markets: estimation of macro yield functions. JARQ, 39, 121-134.

Furuya, J. et al. (2015) Climate change effects on long-term world-crop production: incorporating a crop model into long-term yield estimates. JARQ, 49, 187-202.

Iizumi, T. et al. (2011) Probabilistic evaluation of climate change impacts on paddy rice productivity in Japan. Climate Change,
107, 391-415

Intergovernmental Panel on Climate Change (2013) Working group I contribution to the IPCC Fifth Assessment Report Climate Change 2013: The physical science basis summary for policymakers, IPCC Working Group I, Geneva, Switzerland, pp.36.

Kawatsu, S. et al. (2007) Change of weather condition and its effect on rice production during the past 40 years in Japan. Japanese Journal of Crop Science, 76, 423-432 [In Japanese].

Kobayashi, S. et al. (2012) A study of socioeconomic evaluation methods for climate change adaptation technologies in agriculture. Papers on Environmental Information Sciences, 24, 19-24 [In Japanese].

Kobayashi, S. \& Furuya, J. (2015) Development of a tool for socio-economic evaluation of agricultural technologies directed toward adaptation to climate change. JARQ, $\mathbf{4 9}$, 135-141.

Kunimitsu, Y. (2015) Regional impacts of long-term climate change on rice production and agricultural income: evidence from computable general equilibrium analysis. JARQ, 49, 173-185.

Peng, S. et al. (2004) Rice yields decline with higher night temperature from global warming. Proceedings of the National Academy of Sciences of the United States of America, 101, 9971-9975.

Tran, T. A. \& Daim, T. (2008) A taxonomic review of methods and tools applied in technology assessment. Technological Forecasting \& Social Change, 75, 1396-1405.

West, J. W. et al. (2003) Effects of hot, humid weather on milk temperature, dry matter intake, and milk yield of lactating dairy cows. Journal of Dairy Science, 86, 232-242.

Yagi, K. (2013) Preface to the special issue "Mitigation greenhouse gas emissions from agriculture." Soil Science and Plant Nutrition, 59, 1-2. 